\title{
Importance of Financial literacy For Sustainable Future Environment: A Research Among People In Rural Areas With Special Reference To Mandi District,Himachal Pradesh
}

\author{
Sunita Kumari, Ampu Harikrishnan \\ Business Management, Indus International University, Una, India \\ *Corresponding author E-mail: sunitakumari.iiu@gmail.com
}

Manuscript received 1 Jan 2021; revised 10 Jan 2021; accepted 15 Jan 2021. Date of publication 20 Jan 2021

\begin{abstract}
Education and Role of technology is a right combination that allows the people to make the right decision for sustainable development. It has been observed that financial education is a challenge globally. Financial education plays fundamental role for better understanding the needs of combat climate change. Education and Environmental awareness are important to create global networks among the different corporation that include public and private sectors. Financial literacy is closely connected with sustainable growth of economy. Sustainable behaviors of individuals are required for ensuring the sustainable development in the society. This paper is to discuss the importance of financial literacy for sustainable future Environment. It deals with the concept of financial literacy, sustainable development and to study the respondent demographic profile as well as the knowledge about financial literacy for sustainable future environment. The paper is designed is on Primary data and secondary data. Primary data is collected through survey. A questionnaire is used which is most common tool for collection of data. Secondary data is gathered through various reports, Articles, journals or through literature review focus on financial literacy for sustainability.This paper analysis important of financial literacy for sustainable future environment with special reference to Rural people of particular District of Himachal Pradesh. This study has covered only one district of Himachal Pradesh.
\end{abstract}

Keywords: Financial Literacy; Behavior; Financial Education; Sustainable Development; Climate Change

\section{Introduction}

Financial literacy has been identified as a knowledgeable resource for appropriate decision making but insufficient attention is given to how financial literacy affect the environmental sustainability. [1] The resource-based view (RBV) posits that a firm's competitive advantage and performance are dependent on its tangible and intangible resources. To preserve their competitive advantage firms, need a wide range of resources and a wide knowledge base

Education is a one of the main component of financial literacy that affects the environment globally. [2] According to Hogarth (2006), financial education is considered differently by different people. Some people would esteem themselves as financially educated if they possess quite a broad range of financial knowledge as understanding complicated macroeconomic issues and their effect of everyday household financial decisions. At the same time, others would focus exclusively on basic routine money management. However, apparently financial education covers both macro and narrow ranged topics. The growth of Sustainable development is possible through proper educational channel. Financial literacy is a demand of society for making an appropriate decision regarding various resources. Financial literacy helps to promote the growth of economy. Environment is influenced by various factors such as social, political, economic, technologies, international trade so on so forth. Education and environmental awareness plays important role to create a global network among different sectors of the economy.

Commission on environment and development, 1987 ensuring the sustainable development on society needs an individual's to react in a sustainable manner. This is of course; apply to the financial literacy and handling the funds this paper deals with the importance of financial literacy for the society. 


\section{Literature Review}

\subsection{Financial Litercay And Sustainable Future Environment}

Financial literacy: The word literacy is totally different from the financial literacy. There is a difference between literacy and financial literacy. Literacy simply means one who can read and write but the term financial literacy is broad concept which includes various skills, financial knowledge, attitude and behavior for taking right decisions regarding sustainable development. Financial literacy has become now important research topic in connection of social accountability and responsibility. Sustainable future Environment: sustainable future means where a people can meet their basic requirements without compromising the ability of next generations to meet their own requirements. Environmentally sustainability covers various global issues such as climate change, water management, soil, water pollution etc. financial education plays vital role for better understanding the needs of combat climate change.

\subsection{Importance Of Financial Literacy For Society}

Financial literacy ensures the financial stability of individuals. Financial literacy is economic indicator which can be monitored in all over the world. Sustainable fiancé, CSR, financial education, financial performances have become central issues in measuring the growth of economy. Moreover one of the important issues now days is the depletion of natural resources. Several studies have been shown the link between CSR, financial education. Intellectual capital and financial performance on the market place. [3]Sustainability involves the adaptation of today's business model to the constantly changing Economic, financial, social, political, and demographic context, making sure that limited resources (Financial, physical and human) are being used responsibly and efficiently in order to permanently. Improve individuals' lives as well as strengthen organizations' relationships with the environment. However, any type of existing activity as well as any type of organization (either public or private).

Based on capital - a fundamental asset, in the absence of which both would cease to exist. [4]Sustainability is not just an aspect that is important in public health, but rather it is a prerequisite for health. Climate change, the peaking of oil, and ecosystem degradation threaten food shortages, displacements, new disease vectors and resource conflicts, all of which have serious impacts on health. At the same time, the habits of overconsumption which are the root cause of un-sustainability threaten obesity and a variety of mental and physical illnesses related to a sedentary lifestyle. This article considers the skills and attributes that learners will need to gain in order to survive and thrive in the 21 st century in ways which contribute to sustainability. These skills and attributes are referred to using the shorthand term of 'sustainability literacy'. [5]Sustainability literacy' follows in the footsteps firstly of 'environmental literacy' and then 'ecological literacy'. The thrust has been away from a narrow focus on environmental pollution, towards wider concerns with how the environment can provide basic necessities for current and future generations. As a consequence, the trajectory has been for definitions of the new form of 'literacy' to become less specific and more general in scope. To illustrate, consider Orr's characterization of 'ecological literacy', which represents a half-way point:

Ecological literacy...implies a broad understanding of how people and societies relate to each other and to natural systems, and how they might do so sustainably... [It also implies] an understanding of concepts such as carrying capacity, overshoot,... thermodynamics, tropic levels... magnitudes, rates, trends of population growth, [and] species extinction... Ecological literacy requires a comprehension of the dynamics of the modern world. [7] The sustainability agenda and construction are intricately linked. The rationale, therefore, for embedding sustainability within the construction curriculum is powerful. Strong policy drivers for embedding sustainability in the curriculum also exist, but the response from construction educators is thus far patchy. However, the case study demonstrates that integrating sustainability issues within construction courses is readily achievable.[8] In this article we review the literature on financial literacy, financial education, and consumer financial outcomes. [9] Massive growth is threatening the sustainability of cities and the quality of city life. Mass urbanization can lead to social instability, undermining the capacity of cities to be environmentally sustainable and economically successful. A new model of sustainability is needed, including greater incentives to save energy, reduce consumption and protect the environment while also increasing levels of citizen wellbeing. Cities of the future should be a socially diverse environment where economic and social activities overlap and where communities are focused around neighborhoods. They must be developed or adapted to enable their citizens to be socioeconomically creative and productive. [10] Currently, from the perspective of educational practices, the methods used to teach the next generation to be fully responsive, politically, socially, ecologically, and historically, towards a sustainable way of living have become critical. This requires a major shift in attitude. We need to create more open-minded generalists who can see the complex connections to realize such a way of life instead of narrowed-minded specialists. The Life and Sustainability course at Thammasat University offers opportunities to multi-disciplinary students to shape and share their ideas on sustainability issues and longterm goals.[11] he overall findings suggest that the environmental preservation, economic growth and related topics have an impact on Earth are becoming more and more important today. The attitude of the corporate, government and the students is witnessing a change. Though the awareness is there, yet the level of contribution of both the corporate and the institutes is very low. It also came to light that most of the students realize that environmental education should definitely be an intrinsic part of business paradigm.

[12] The present paper supports the idea that education for sustainability should emphasize on future thinking, envisioning the future creatively, and building on the conversation of public engagement and empowerment. In doing this, the paper fills a gap by analyzing and discussing the young generation's perceptions and learning outcomes on the basis of their sustainable concepts and models.

[13] Even though different cities face different issues and scales of challenges, the concepts to tackle the sustainability challenges have already been explored. 'Sustainable city' is a considerably broad concept; it has attracted the most academic attention in this field. Other city and model concepts related to sustainability, such as 'Smart city', 'Digital city', 'Eco city', 'Green city', 'Low carbon city', 'Knowledge city', and 'Resilient city' have also been in the spotlight, while the concepts of 'Intelligent city', 'Ubiquitous city', 'Live able city', and 'Information city' are relatively new (Jong et al., 2015).

\section{Materials \& Methods}

- Both primary as well as secondary data are used for the sake of study.

- Exploratory research design is used in present study 
- A structured Questionnaire is prepared for collecting the information from people of rural areas of Mandi District.

- Mandi District of H.P is considered as research area for the study.

- Total sample size of the study was 100 respondents, these respondent were the women living in rural areas of the selected research area.

- 100 respondent are taken as a sample for effective study

- Convenient sampling technique is used for selecting the sample.

MS Excel is used for analyzing data and present in the form of tables and graph

\section{Results and Discussion}

Table.1. Percentage of Age Groups

\begin{tabular}{ccc}
\hline Age Groups & Frequency & Percentage (\%) \\
\hline Below 20 & 27 & 27 \\
\hline $20-30$ & 40 & 19 \\
\hline $30-40$ & 14 & 19 \\
\hline 40 and above & 100 & 100 \\
\hline Total & & 14 \\
\hline
\end{tabular}

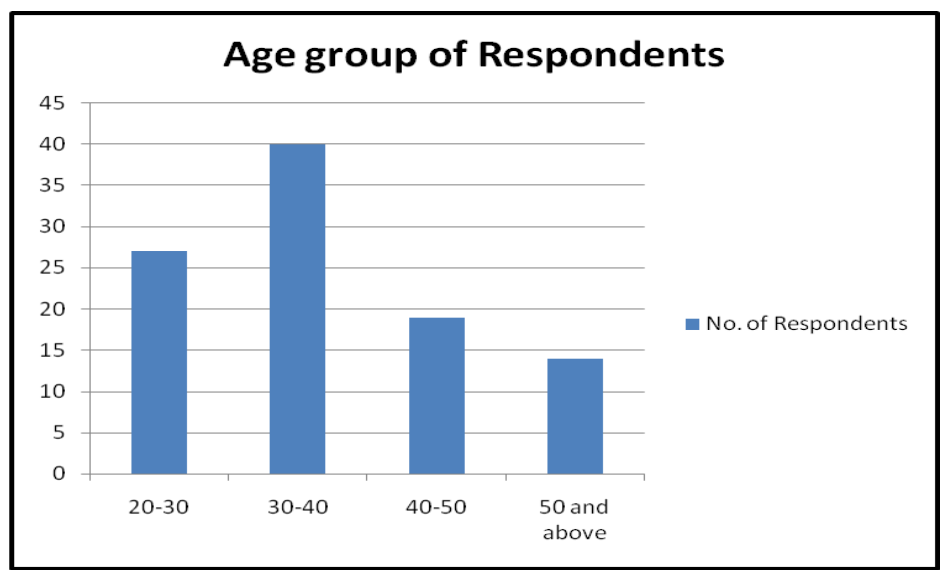

Fig. 1. Age Groups of Respondents

Table 2. Education of the Respondents

\begin{tabular}{ccc}
\hline Education & No. of Respondents & Percentage $(\%)$ \\
\hline Illiterate & 24 & 44 \\
\hline Primary level & 40 & 19 \\
\hline Secondary level & 17 & 19 \\
\hline Graduation and Above & 100 & 100 \\
\hline Total
\end{tabular}

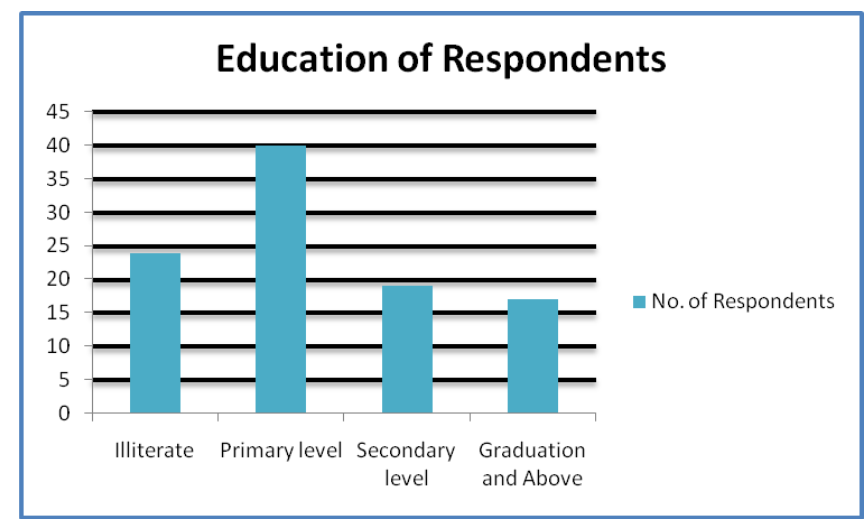

Fig. 2. Education of Respondents 
Table 3. Monthly Income of Respondents

\begin{tabular}{ccc}
\hline Income & No. of respondents & Percentage (\%) \\
\hline Less than 5k & 06 & 06 \\
\hline 5k-10 k & 19 & 19 \\
\hline $10 \mathrm{k}-15 \mathrm{k}$ & 40 & 40 \\
\hline 15k and above & 35 & 35 \\
\hline Total & 100 & 100 \\
\hline
\end{tabular}

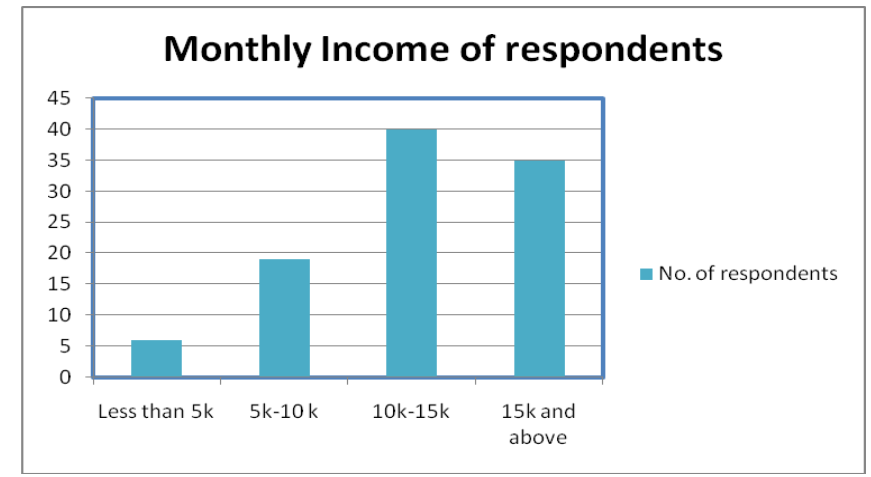

Fig. 3. Monthly Income of Respondents

Table 4. Marital status of respondent

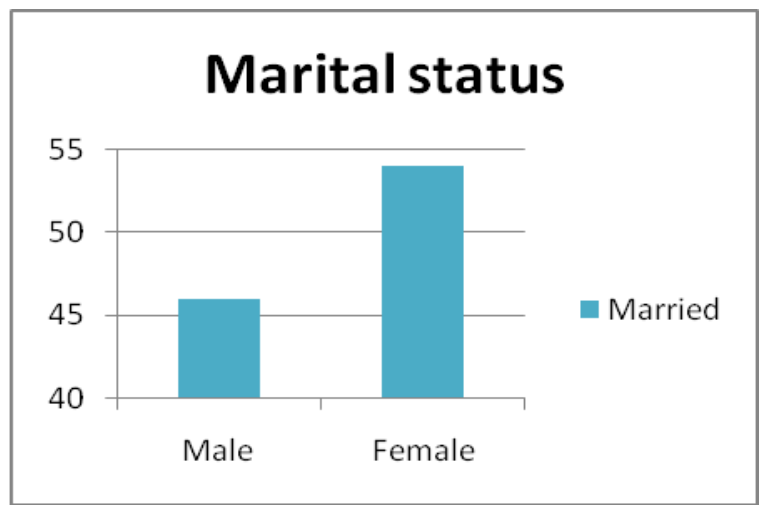

Fig. 4. Marital Status of Respondents

Some Important questions asked to know about the importance of financial literacy on sustainable Environment future from the respondents

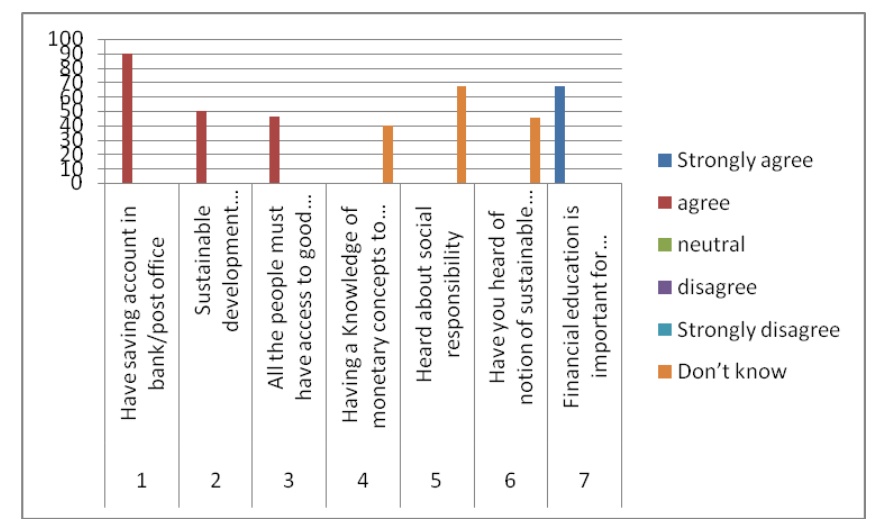

Fig. 5. Results of Awareness of Financial Literacy

The above figure shows that the result of awareness of financial literacy and sustainable future environment in which most of the respondents(male and female) are aware about financial matters but they have less interest or less aware about sustainable developmental issues or environmental issues. 


\section{Conclusion}

The issue of Importance of financial literacy on sustainable future environment related to rural people of District Mandi of H.P is an important issue in the present scenario because individuals are getting a number of opportunities in various fields such as in education, entrepreneurship, SHGs, economy etc. Most of working women and men of rural areas are very much aware about financial inclusion schemes such as pradhan mantra jan dhan yojana(PMJDY) and they have knowledge about financial matters also. Only knowledge of financial matters are not necessary but how to attain maintain and retain our natural resources also very important for the future growth of generations. Proper utilization of funds in saving or growing the environment is one of major challenge for the economy. Apart from that there is need to provide awareness through seminar or providing financial education to all the people for both financially well being as well as for society welfare. Financial literacy seminars promotes the standards for transparency, fairness and customer care in market place that respect the local culture and traditions, pursue a long term vision for sustainable win win relationships with all the stakeholders.

\section{References}

[1] Ye, J., \& Kulathunga, K. "How Does Financial Literacy Promote Sustainability in SMEs? A Developing Country Perspective. Sustainability”, 11(10), 2990. 2019. doi: https://doi.org /10.3390/su11102990

[2] Gaisina, S., \& Kaidarova, L. "Financial Literacy of Rural Population as a Determinant of Saving Behavior in Kazakhstan". Rural Sustainability Research, 38(333), 32-42. 2017. doi: https://doi.org /10.1515/plua-2017-0010

[3] Raluca Gh. Popescu, \& Popescu. "An Exploratory Study Based on a Questionnaire Concerning Green and Sustainable Finance, Corporate Social Responsibility, and Performance: Evidence from the Romanian Business Environment”. Journal of Risk And Financial Management, 12(4), 162. 2019. https://doi.org/10.3390/jrfm12040162

[4] Ansari, W., \& Stibbe, A. "Public Health and the Environment: What Skills for Sustainability Literacy - And Why?". Sustainability, 1(3), 425-440. 2009. https://doi.org/10.3390/su1030425

[5] Ansari, W., \& Stibbe, A. "Public Health and the Environment: What Skills for Sustainability Literacy - And Why?". Sustainability, 1(3), 425-440. 2009. https://doi.org/10.3390/su1030425

[6] Kothari, C. Research Methodology. New Age International. 2019.

[7] Mdpi.com. (2020). Retrieved 1 July 2020, from https://www.mdpi.com/2071-1050/11/10/2990/pdf.

[8] Murray, P., \& Cotgrave, A. "Sustainability literacy: the future paradigm for construction education?". Structural Survey, 25(1), 7-23. 2007. https://doi.org/10.1108/02630800710740949

[9] Hastings, J., Madrian, B., \& Skimmyhorn, W. "Financial literacy, financial education and economic outcomes". National Bureau of Economic Research. 2012.

[10] Riffat, S., Powell, R., \& Aydin, D. "Future cities and environmental sustainability". Future Cities And Environment, $2(0), 1$. 2016. https://doi.org/10.1186/s40984-016-0014-2

[11] Likitswat, F. " Future Cities: New Generation's Visions of Sustainability Concepts and Models. Future Cities And Environment, 5(1). 2019. https://doi.org/10.5334/fce.61

[12] Singhal, N. "Environment Sustainability in Business Education: Future Manager's Perspective". SSRN Electronic Journal. 2012. https://doi.org/10.2139/ssrn.2140652

[13] Likitswat, F. "Future Cities: New Generation's Visions of Sustainability Concepts and Models. Future Cities And Environment", 5(1). 2019. https://doi.org/10.5334/fce.61

[14] De Jong, M., Joss, S., Schraven, D., Zhan, C., \& Weijnen, M. "Sustainable-smart-resilient-low carbon-eco-knowledge cities; making sense of a multitude of concepts promoting sustainable urbanization". Journal of Cleaner Production, 109, 25-38. 2015. https://doi.org/10.1016/j.jclepro.2015.02.004

[15] T., D. "Financial Literacy and Inclusive Growth: Challenges and Opportunities". SSRN Electronic Journal. 2017. https://doi.org/10.2139/ssrn.2985436

[16] Kothari, C. Research Methodology. New Age International. 2019. 